\title{
El grabador checoeslovaco Koloman Sokol (1902-2003) en México y su enseñanza ${ }^{1}$
}

The Czech-Slovak engraver Koloman Sokol (1902-2003) in Mexico and his teaching Pavel, Štěpánek ${ }^{2}$

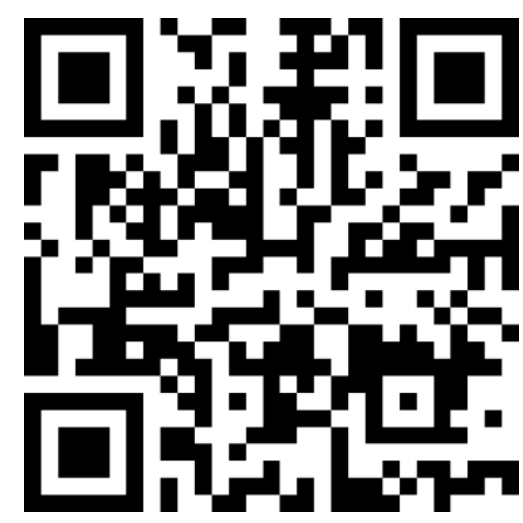

.................................

Fecha de recibido: 24-03-2021

Fecha de aceptado: 30-05-2021

\section{(c) BY-NC-ND}

Esta obra está bajo una licencia de Creative Commons Reconocimiento-NoComercialSinObraDerivada 4.0 Internacional

\begin{abstract}
RESUMEN
El presente trabajo tiene como objetivo es describir y recordar la importancia de un artista europeo activo en la ciudad de México entre los años 1937 y 1941. El presente artículo es una investigación de carácter cualitativo y el enfoque es documental, donde se aplicó el método de búsqueda de obras originales en colecciones mexicanas, sus exposiciones en México, son producto de una revisión documental de la vida y la obra del grabador checoeslovaco Koloman Sokol (1902-2003), con la técnica de investigación de la revisión documental completa de los ecos aparecidos en la prensa diaria, revistas especializadas o monografías existentes sobre el artista para valorar el impacto de su obra en el ambiente mexicano. Se encontró que el artista, a pesar de su larga vida, no ha sido todavía tan estudiado precisamente en su etapa mexicana. Se concluye que su obra deberá estudiarse aún no solo desde el punto de vista de los datos históricos, sino también la temática mexicana que se prolonga hasta el final de su vida, medio siglo después de abandonar México, testimonio del impacto de las realidades del país donde enseñó las técnicas del grabado a invitación del gobierno mexicano.
\end{abstract}

Palabras claves: Arte, enseñanza, grabador checo-eslovaco, Koloman Sokol, México.

\begin{abstract}
This work aims to describe and remember the importance of a European artist active in Mexico City between 1937 and 1941.This article is a qualitative research and the focus is documentary, where the method of searching for works was applied originals in Mexican collections, his exhibitions in Mexico are the product of a documentary review of the life and work of the Czech-Slovak engraver Koloman Sokol (1902-2003), with the research technique of a complete documentary review of the echoes that appeared in the daily press, specialized magazines or existing monographs on the artist to assess the impact of his work on the Mexican environment. It was found that the artist, despite his long life, has not yet been so studied precisely in his Mexican stage. It is concluded that his work should still be studied not only from the point of view of historical data, but also the Mexican theme that lasts until the end of his life, half a century after leaving Mexico, testimony to the impact of the country's realities. Where he taught engraving techniques at the invitation of the Mexican government.
\end{abstract}

Keywords: Art, czecho-Slovak graphic artist, Koloman Sokol, Mexico, teaching.

Cómo referenciar este artículo:

Štěpánek., P. (2022). El grabador checoeslovaco Koloman Sokol (1902-2003) en México y su enseñanza. Revista Política, Globalidad y Ciudadanía, 8(15), 92-113. https://doi.org/10.29105/pgc8.15-5

\footnotetext{
${ }^{1}$ Este artículo es producto del proyecto "El grabador checoeslovaco Koloman Sokol (1902-2003) en México y su enseñanza" iniciado en 2020.

${ }^{2}$ Universidad Palacký, República Checa. Doctor por Universidad Carolina. Profesor investigador en el Departamento de Arte e Historia de la Universidad Palacký, Email: estepanek@tiscali.cz y https://orcid.org/0000-0001-9505-9547.
}

92 Revista Política, Globalidad y Ciudadanía| Vol. 8, Núm. 15, enero - junio 2022 | ISSN 2395-8448 | http://revpoliticas.uanl.mx/ 


\section{1. - INTRODUCCIÓN}

Resulta sorprendente que el grabado mexicano moderno tuvo mucho que ver, en sus momentos de formación moderna, con el checoslovaco. Es que el artista Koloman Sokol, eslovaco de nacimiento, pero formado con definitiva en el ambiente checo, en Praga, interviene en el momento importantísimo del surgimiento de la famosa escuela mexicana del grabado, al margen del Taller de Gráfica Popular y cuya base ha sido la conferencia pronunciada por el autor (Pavel Štělpánek) en la cátedra José Clemente Orozco del Instituto de Investigaciones Estéticas de la UNAM que le fue ofrecida en 1982 (Obra que aún no ha sido publicada en México en versión breve, sí ha aparecido en Praga, en castellano) (Štěpánek, 2002).

Poco después de regresar de mi estancia en México, publiqué un brevísimo artículo en 1985 “Koloman Sokol a mexická grafika / K. Sokol y el grabado mexicano” y el artículo que ahora presento, está totalmente reelaborado y puesto al día, finalmente trato el tema en un capítulo de mi libro “Relaciones artísticas entre la República Checa y México”. En Checoslovaquia, la obra de Koloman Sokol despierta interés constante, y es apreciada ya a principios de los años treinta, apenas terminados sus estudios, es en el segundo lustro de este decenio que Sokol aparece y permanece en México.

Luego, después de la segunda guerra mundial, cuando el artista regresa a Checoslovaquia desde su exilio en Estados Unidos, donde se refugió en plena guerra desde México, en su Eslovaquia natal es nombrado Académico Ordinario de la Academia Eslovaca. Sin embargo, pronto, al reconocer la amenaza que se desprendía de la toma del poder por los comunistas en 1948, vuelve a Estados Unidos desde París. Fue un momento en el que se imponen, en suma, criterios del "realismo socialista" dogmático al estilo soviético, pregonizado oficialmente por el sistema comunista en la época estalinista. Para sorpresa, Sokol, como artista comprometido con los criterios de lo social en las artes plásticas, estrictamente figurativo, además, aunque con carga expresionista, es tenido por el nuevo sistema comunista como un "vulgar formalista burgués".

A la medida en que el sistema, tras la muerte de Stalin en la misma época, en México se publica un libro que describe los criminales métodos de Stalin (Orlov, 1956), en el que suaviza los criterios, cuando se rompe la gran hostilidad del régimen para con los artistas checos residentes en el extranjero, por lo menos en cuanto a la emigración anterior al régimen comunista, Sokol goza de gran atención en 
Štěpánek., P.

los años sesenta, y finalmente, en los años setenta, cuando se le organizó una magna exposición en la Galería Nacional de Praga (Koloman, 1978). En este momento culminó su rehabilitación a nivel checoslovaco. Más tarde, al separarse Eslovaquia, continúa su integración en la cultura nacional eslovaca.

\section{2.- FUNDAMENTO TEÓRICO}

\section{Breve Biografía}

Mediante el trazo brevemente a modo de introducción, los datos básicos del artista de quién vamos a hablar hoy: Koloman Sokol (1978) Nació el 12 de diciembre de 1902 en la ciudad eslovaca de Liptovský Sv. Mikuláš y murió en Tucson (Arizona, Estados Unidos), el día 13 de enero de 2003, al quedar huérfano su tío le enseña oficio de carnicero en la ciudad de Košice. Hacia 1921 sin embargo, aprende por las noches grabado en cursos impartidos por Eugen Krón, emigrante húngaro que vivía en la misma ciudad, dos años más tarde en 1923, tras una exposición de alumnos del taller de Krón, es recomendado para estudiar en la Academia de Artes Plásticas de Praga, donde le aceptan en el segundo intento de ingreso en 1925, en la escuela del profesor Jakub Obrovský. Durante el segundo y tercer año (1926-1928) estudia en el taller de grabado del profesor Max Švabinský.

En 1927 fue su maestro Jan Rambousek, asistente del profesor Max Švabinský, y máximo exponente del grabado social de los años veinte en Checoslovaquia, posteriormente Koloman Sokol encontró su mejor intérprete en la historiadora Eva Šefčáková (1964), Koloman Sokol, Bratislava. La bibliografía sobre Sokol es muy larga, me he limitado a los trabajos más logrados, renovando la bibliografía surgida últimamente. Sokol termina sus estudios en 1931 y el mismo año, el público conoce por primera vez sus obras en Praga cuando expone con el grupo Hollar, luego en la exposición anual de la Academia y en octubre del mismo año en las salas de del grupo Mánes donde en la exposición del arte eslovaco se presenta como único expositor de grabados, confirmando así que fue el primer artista de Eslovaquia que dedicó su talento por completo al grabado.

Por iniciativa del profesor Tavík F. Šimon, Sokol pide el 16 de junio de 1932 una beca para estudiar en el extranjero: la recibió para una estancia de tres meses en París y gracias al mismo profesor se quedó en París hasta el final del año 1933, recibe esta beca apenas habiendo terminado la Academia y significó para él un periodo de plena satisfacción interior. 
El año 1936, es para él un año de numerosas exposiciones: decisiva es su participación en la exposición del Grabado checoslovaco en el Palacio de Bellas Artes de la Ciudad de México, que luego continúa en Guatemala, Honduras, Nicaragua y El Salvador, finalmente participa en la Exposición del grabado internacional en Los Ángeles y otras.

La exposición en México fue organizada por la Sociedad de la Amistad Mexicano-Checoslovaca, un miembro de la misma Francisco Díaz de León (Blaisten, 2011), director de la Escuela del Arte del Libro, pidió mediante la embajada checoslovaca en México ayuda para el intercambio de artistas entre los dos Estados, se requería un grabador de orientación moderna que pudiera ir a México durante un año con fines pedagógicos.

Sokol aceptó la invitación para México, el 25 de mayo de 1937 salió de Praga, a través de Hamburgo y Veracruz rumbo a México, donde llegó el 20 de junio de 1937, aquí se desarrolló inmediatamente su actividad de profesor en la Escuela de las Artes del Libro, en la Ciudad de México. La escuela estaba dirigida por Francisco Díaz de León y se enseñaba allí la tipografía, la encuadernación, la ilustración de libros, la técnica del grabado, etc., Sokol fue encargado de la dirección de la cátedra del grabado.

\section{Su Obra Anterior al Viaje a México}

Como la primera etapa, la de la formación del artista aparentemente no tiene nada que ver con México, le prestaremos por lo menos un poco de atención. Situemos a nuestro artista primero en el panorama checoslovaco: Perteneció a la generación que siguió a los fundadores del arte moderno eslovaco; salió a la escena cultural a fines de los años veinte, cuando en Checoslovaquia culmina la corriente del arte social. Este periodo estaba todavía lleno de entusiasmo romántico para con los motivos nacionales que han sido revividos y han servido como estímulo a los artistas. Sin embargo, desde sus días estudiantiles Sokol perteneció a los más escépticos intelectuales jóvenes en este sentido. El folklore no es para él una visión idealizada o falsa del pueblo, sino que le sirve para abrir los ojos y abrírselos a otros para ver con toda claridad la realidad social.

A Sokol se le señalaba erróneamente como el primero - y hasta los años treinta como el únicoautor que en Eslovaquia se dedicaba a temas sociales, pero el elemento de la crítica social se puede observar prácticamente en todos los grandes exponentes del arte eslovaco. Ningún artista sensible y responsable pudo pasar por alto la injusticia sin enfrentarla dándole forma de género popular, pero sí 
Štěpánek., P.

puede afirmarse que antes de Sokol nadie estuvo tan dispuesto a luchar contra la injusticia, luchar tan sin reservas y con toda su obra (como este grabador) interesado por la ciudad y su vida social ya desde el mismo inicio de sus primeros intentos artísticos serios (Šefčáková, 1964, p. 13).

No poco, aunque indirecto, mérito en la cristalización de la actitud artística y cívica de Sokol tienen los dos maestros suyos en la Academia de Bellas Artes de Praga - Max Švabinský y T. F. Šimon, que ayudaban a su desarrollo independiente. Además, Sokol se encuentra directamente ligado con Jan Rambousek, el principal artista de la escuela social, entonces asistente de Šimon, quien representó para Sokol el vivo contacto con el grabado social checo de esta tendencia creativa tan atrayente.

Sokol se muestra interesado por los destinos difíciles y los conflictos psíquicos, que culminan en una catarsis revolucionaria, como lo vemos en Familia y una de las primeras versiones de Revolución (ambas realizadas en 1928), a pesar de una composición estática.

En la xilografía Rebeldes (1929) aumenta la dinámica de movimientos psicológicos que llena las figuras nudosas de energía e ira (Šefčáková, 1964 p.17). La senda de la actividad gráfica de Sokol después de terminar los estudios en la Academia de Praga, la definen las xilografías El Pescador y la profundamente humana Tres reyes magos (ambas de 1933). A los trabajos más estremecedores de esa época pertenecen xilografías para la novela de la escritora eslovaca Margita Figuli Hatillo de calor (“Uzlík tepla") que aparecieron en 1936; Sokol interpreta el modelo literario drástico, que es una acusación de la época, llena de odio y desesperación, con el mismo espíritu y rudeza. Hay que aclarar que Eslovaquia fue la parte más pobre de Checoslovaquia, prácticamente tierra de campos y montañas, sin industria, cuando se unió al nuevo estado - Checoslovaquia - en 1918, dentro del cuál subió su nivel intelectual y material vertiginosamente y es muy difícil traducir el título de la obra, que sugiere ternura del hogar materno donde no hay nada más que el calor, y encubre así la significación drástica que tiene: la de denunciar la terrible pobreza (Šefčáková, 1964 p. 20).

\section{Sokol en México}

El éxito del joven grabador (de 34 años) en la exposición del grupo Hollar en México en 1936, donde aparece con sus arriba citados maestros, decide su futura suerte en el citado catálogo del Grupo Hollar de 1936, cuando el gobierno mexicano invita al país a Koloman Sokol como profesor de artes gráficas, lo formula con las siguientes palabras: "Queremos a un artista que sea de los más modernos, como Sokol, 
representado por sus obras en la exposición del grupo Hollar en México (LM, 1962). Lo explica a posteriori el propio Díaz de León, de manera breve y convincente, así que vamos a transcribir sus palabras:

"Visitando la exposición del grabado checoeslovaco que tuvimos la oportunidad de ver en 1936, como muchos de nuestros artistas, asistí en la quietud de una tarde tarde de invierno a la valorización técnica de las obras expuestas. Naturalmente, el valor de ellas incitaba a sorprender "el secreto" de su realización, y una por una, fue analizada: Cyril Bouda, xilografo, acuafortista, o burilista a voluntad; Kobliha, romántico a la manera grandiosa de Gustavo Doré, con un dominio precioso del oficio. Carlos Vick (en realidad, Karel Vik, nota PŠ), dominando el procedimiento del color con gran maestría; Fiala, con grave acento... pero la obra más humana, más dolorosa, más conmovedora y al mismo tiempo, más pura, solamente la sorprendí en Koloman Sokol. Allá, en la penumbra del salón, admiraba yo la disciplina de este grabador, que, a fuerza de tallas ordenadas, ha sabido expresar la rebeldía y el dolor del pueblo. El grabado de Sokol es, por su tema, universal. Por esto mismo encuentro en las mismas multitudes hambrientas, en los rostros transfigurados por la pasión, por el odio o por el horror, al artista checoslovaco más proximo a nuestro arte mexicano. Sus maderas - más que aguafuerte o litografía - me parecen el mejor lenguaje del artista, y él sabe arrancar con el burril, escudriñando, hiriendo o recortando, la entraña de la madera. Como la mayoría de los artistas de su país, Sokol domina las téncicas gráficas y ha sabido servirse de ellas noblemente, para la estampa y la ilustración. El libro de edición limitada de las sociedades de los bibliófilos, y también el libro proletario, han conocido el trabajo de Sokol, y en ambos ha impreso su huella dolorosa. En México donde apreciamos el grabado, porque estamos familiarzados con él, estimaremos calurosamente la obra de Sokol, la de este camarada en lucha que nos trae su mensaje de rebeldía (Blaisten, 2011).

A la Escuela de las Artes del Libro acudieron numerosos alumnos de otras escuelas, incluso artistas profesionales del país y del extranjero para perfeccionarse en las técnicas del grabado, Sokol les enseñaba a dominar teórica y prácticamente todas las técnicas del grabado.

Por su actitud humanista y excelentes facultades pedagógicas era muy estimado en México, no solamente por sus alumnos, a los cuales muchas veces ayudaba incluso económicamente, sino también por los máximos exponentes de la cultura. Dejemos la palabra al profesor Francisco Díaz de León, director de la Escuela de las Artes del Libro: "A sus conferencias acudían muchos alumnos y artistas 
Štěpánek., P.

profesionales mexicanos y extranjeros, que querían perfeccionarse en las tecnologías de grabado, el maestro Sokol fue ejemplar por su honradez y solidez en el trabajo pedagógico...” El propio Sokol declara: "El secreto de mis éxitos pedagógicos en México consistió en el hecho de que yo no tenía ningún secreto delante de mis alumnos" (Šefčáková, 1963). Según Sokol, esos cinco años pasados en México fueron los más hermosos de su vida, en los cuales adquirió un respeto hacia sí mismo y hacia otros, y trabó las amistades más profundas con gente cordial, apasionadamente buenas. El periodista Ruppeldt también dice que a Sokol "le halaga el reconocimiento de México y la carta del presidente mexicano (Šefčáková, 1963). (En realidad, se trataba de una carta - nombramiento de profesor de categoría "A", del día 9 de octubre de 1941 que en nombre del presidente fue firmada por el prof. Ismael Cabrera Martínez), palabras de admiración que aparecen en este o aquel periódico después de presentarse en alguna que otra exposición... Koloman habla con entusiasmo sobre México, platica cordialmente sobre decenas de acontecimientos dramáticos y humanos del país que le dio conciencia de sí mismo, donde le apreciaron y quisieron, y al cual él dio muchísimo".

Lo confirman otros testimonios mexicanos, veamos todavía uno difundido en Checoslovaquia, tanto más interesante cuanto que su autor Gillermo Rivas, compara a Sokol con Orozco, aunque dice que es una "coincidencia espiritual casual de dos artistas contemporáneos, que miran la realidad desde un punto de vista próximo y entienden su misión de manera similar..."

"Sokol vino a México como una personalidad cristalizada - continúa Rivas - tan cristalizada que estaba al límite de un intenso individualismo. Y es interesante apuntar que antes de venir a México, ni siquiera conocía la obra de Orozco” (Ruppeldt citado en Beňovský, 2009).”

"Desde el renacer del arte mexicano vinieron a nuestro país muchos artistas extranjeros, para beber en nuevas fuentes y buscar (encontrar) nuevas ideas y orientaciones, pero la presencia de Koloman Sokol se mostrará con un efecto probablemente contrario. La fuerza y el peso de su técnica, la verdad de sus temas simplemente expresada, la verdad -que en estos días de traición y de pompa fugaz es realmente una vuelta a la fidelidad- es casi por cierto un aporte de nueva vitalidad, de un estímulo nuevo y fuerte para el arte mexicano contemporáneo.” (Rivas,1940).

Limitar la salida de Sokol para México meramente a su posición material, como intentaba explicarlo la prensa checa de entonces, era por lo menos malicioso -y el propio Sokol refutó esta interpretación en la revista Elán (Šefčáková,1963). Aunque las perspectivas de una posible creación 
artística libre, asegurada materialmente, no dejan de tener importancia, a Sokol le impulsa a México el afán eternamente joven de conocer, documentado y no pocas veces subrayado en su correspondencia con la familia.

Y luego, en su decisión influyen, sin duda fuertemente, relaciones familiares surgidas de la boda con la checo-americana Lydia Kratinová. Por esta razón Sokol acoge la posibilidad de un intercambio de trabajo por un año con alguno de los artistas mexicanos, después de esmerados preparativos para la nueva actuación pedagógica, incluyendo el estudio del español.

Todos quienes analizan la obra de Sokol, coinciden en que Sokol no ha cambiado mucho su actitud y que "los temas que escogió del ambiente mexicano no difieren sustancialmente de aquellos de los que se ocupaba en su natal Checoslovaquia” (Rivas, 1940). La verdad es qué, al llegar a México, termina en su obra el periodo de la cristalización primitiva que comienza en 1930.

Su alumno eslovaco más importante, Vincent Hložník, que también visitó México (aunque mucho más tarde), dice: "Koloman Sokol fue la consciencia. Fue un hombre que miraba fija y concentradamente; un hombre que se paró al final de una calle para echar una ojeada, y vio. Y lo que vio, nos lo mostró, incluso nos lo echó ante los ojos: he aquí el Hombre. El hombre matado, destruido por sus prójimos. (Hložník, s.f.).”

“...Incluso en México, adonde se fue, Sokol quedó tal como era. Dado su carácter, pudo haber ocurrido de otra manera. El corazón, los ojos y la mano no cambian. (Esta frase sirve como título al artículo de Malecová, J. (1973), "Srdce, oči a ruka sa nemenia”, Život, 12, XXIII, no. 2, 10.1 "También en México, adonde se fue desde nuestro país, permaneció fiel a sí mismo. Aquellos que le admiraban, decían de él: "El corazón, los ojos y la mano no cambian." El hecho de que es justamente un grabador eslovaco quien le muestra al mundo al indio oprimido durante siglos, en su plena desnudez, nos llena de orgullo. El arte de Sokol desenmascara asimismo las causas de tanta miseria y pobreza del hombre. La fuerza de la obra de Sokol abrió los ojos también a sus alumnos mexicanos."). El ojo de Sokol vio también en el paisaje mexicano la oscuridad de la vida. El peso y la oscuridad que pesaron sobre el pueblo indio. También aquí camina y peregrina en busca del Hombre matado. Este se convierte para él en un tema fatal. A mí me llena de orgullo - dice en adelante Hložník (s.f.).- que un grabador eslovaco muestra al mundo la vida del indio en su desnudez, descubierto hasta las capas inferiores... No las nubes altas de la planicie mexicana, sino el peso matador, la tristeza infinita y la lágrima pesada. Todo esto lo ve el corazón comprensivo de Sokol. Otra vez es aquel Koloman Sokol que se paró al final de la calle; para 
Štěpánek., P.

ver. De esta oscura calle de la vida trajo a la luz algo terrible: la verdad sobre el indio, matado durante siglos. No hay alegría, solo oscuridad, la nada, y luego momentos de loca borrachera. En las hojas de Sokol vemos piezas de ese tremendo México."

Koloman Sokol enseñaba a ver la vida también a sus alumnos mexicanos. De este modo terminaron por ver a sus pobres hermanos que perecen en dolencias, sufren en chabolas y peregrinan eternamente en filas, en busca de algo más claro que lo que hay allá de donde salieron. Esta realidad, implacable y tremenda, se converte en el único interés de Sokol... Para él fue el más precioso el sentimiento de que había abierto los ojos a sus alumnos y les había obligado a observar lo que él mismo tuvo que ver fatalmente.

Me convence de ello -dice Hložník- el grabado mexicano contemporáneo, el sentido de su derrotero. En el nuevo ambiente, Sokol se encuentra impactado por el pintoresco paisaje mexicano, enredado por leyenda y prejuicios, y por la deconfianza hacia los europeos. En tanto que hombre sensible, recibe desde el principio una cantidad de impresiones nuevas. Influye fuertemente sobre él la cordial acogida. Está entusiasmado por el nuevo conocimiento. Un testimonio directo del tiempo de las primeras impresiones de Sokol son varios dibujos al carboncillo con goma laca del año 1939. Se trata de estudios de figuras, apuntes de desnudos femeninos o de su sensible sobrevaloración estética. La exclusividad de estos trabajos en la obra del grabado radica en la ingenuidad despreocupada que hasta aquel momento no conocíamos en Sokol (Hložník, s.f.).

Desde el aspecto plástico se eslabonan con los trabajos más sonrientes, próximos al dibujo infantil, en su mayoría ilustraciones del bienio 1934-1936. Como ejemplo sirve el redondeado desnudo dignamente gracioso titulado La Mulata, de 1938. La línea de contorno, raramente tranquila, cerrada, determinada, en la obra de Sokol, va completada aquí con una modelación blanda, no descriptiva, modelación tendiente a acentuar la atmósfera. En esto, la creación de Sokol registra uno de sus puntos culminantes.

El día laboral de Sokol en la Escuela del Arte del Libro no tenía prácticamente comienzo ni fin. El grabador se identifica tanto con el grupo de sus alumnos -muy diverso, en principio solo de siete personas, pero que luego aumentó fuertemente-, que pasaba con ellos todo rato libre. Su jefe, colega y colaborador Francisco Díaz de León dice: “Cómo sería posible no recordar al maestro Sokol, si éste nos 
enseñó tan abnegada y abiertamente y supo ser un sincero amigo. Se puede señalar sin exageración, que el maestro Sokol influyó sobre toda la enseñanza del grabado en nuestro país, sobre todo en las técnicas como son todos los tipos de aguafuerte." (Šefčáková, 1963) Por otra parte, en todos los materiales que ha mandado a Bratislava, Koloman Sokol se queja constantemente de Díaz de León, así que debió haber surgido alguna desavenencia entre los dos. En breve, Sokol dice que Díaz de León querría que Sokol y su mujer vivieran en su casa, en Coyoacán, pero Sokol prefirió la calle Rhin, pues estaba a diez minutos de la escuela (en la esquina Colima e Insurgentes, hoy desaparecida). Y también, que querría aprovecharse de los conocimientos de Sokol como suyos, pero Díaz se expresa siempre, en sus textos, de manera positiva de Sokol y su obra.

Con el conocimiento más profundo del país que llega a ser su segunda patria, desaparece de la obra de Sokol toda la despreocupación, típica en los dibujos del autor del año 1938. De la numerosa serie de nuevos aguafuertes asoma ante nosotros un México ya por fin no romántico, el México de una asombrosa pobreza, contrastes y analfabetismo. Este país de fantásticos contrastes llegó a ser el fondo para describir la deseperación humana, la lucha y la muerte.

Sokol fue cautivado por la vitalidad, así como por el fatalismo y la resignación de los mexicanos (Šefčáková, 1963). Ahora toma la palabra la compasión del autor para con los abandonados y los que viven en condiciones de injusticia, tanto más fuerte cuanto más profundamente aprende Sokol a entender las peculiaridades geográficas, económicas y, sobre todo, culturales de un ambiente en un comienzo tan idílicamente visto, y de las tradiciones vitales. De acuerdo con su actuación en la escuela Sokol se concentra en 1939 para aprovechar plenamente y dominar las técnicas de aguafuerte, y halla el eco en la admiración y atención de los artistas mexicanos, a quienes muchas de sus experiencias técnicas resultaban hasta entonces desconocidas e inaccesibles.

La aflicción nostálgica sobre la decadencia humana de las comunidades indias, sobre el hecho de que la civilización de entonces murió en la pobreza, supersticiones y violencias, se hace eco en las hojas de Sokol, como La Vuelta, El Rapto, La Marcha, El Paralítico, La única delicia (todas del año 1939). Su efecto plástico está fundado en el aprovechamiento de la trama de dibujo, en lo compacto de los volúmenes y en la blanda, ricamente matizada modelación de esta construcción la cual puede compararse -a diferencia de una organización interna geométrica- con la arquitectura de piedras duras, pulimentadas por el agua. 
Štěpánek., P.

En varias de estas hojas gráficas suenan reminiscencias del trabajo del maestro de Sokol en Košice -Eugen Krón- y de la construcción rigurosa interna del dibujo del círculo húngaro de esa ciudad eslovaca, al cual Krón pertenecía (Šefčáková, 1964, p.63). El medio ambiente que ya le atraía en su país y para el cual se preparaba con esmero, significó para Sokol una nueva fuente de temas y motivos. Se convirtió en parte suya y casi dejó de sentirse como un extranjero que busca lo exótico. En vez de ello percibía - guiado por su extraordinaria sensibilidad y sentido de la justicia, principalmente social-, incluso las discrepancias naturales del ambiente, la difícil situación de los más pobres y una especial ideología que surge de ella: una incomprensible combinación de lo trágico, la indiferencia y la sumisión mística al destino (Šefčáková, 1964, p. 25).

La inesperada salida de Sokol de la Escuela de Artes del Libro, posiblemente en abril de 1941 sería por unos meses, pues el nombramiento presidencial está fechado el día 9 de octubre de 1941. Por otra parte, en su ausencia le suplían tres alumnos, Vázquez, Savín y Castelar, puede ser que este recuerdo se refiere a la etapa final de su actividad en México. El documento presidencial tenía validez por cinco años, quizás se deba su despedida de la escuela a sus relaciones poco amicales con Díaz de León y está relacionada sin duda alguna con el ambiente general, cuando decae la ola de actividades progresistas y el esfuerzo por hacer accesibles generalmente los valores culturales. La pérdida del puesto (voluntaria, pues la escuela prolongaba el acuerdo siempre con sumo gusto por un año) no significa nada para un grabador de sus calidades y no es un problema de subsistencia, sin embargo, su actividad pedagógica la continuó durante cinco años, como él mismo recuerda.

Pero la pérdida del contacto con la gente joven, a la que introducía con tanta pasión en todos sus secretos, la desaparición paulatina del entorno amistoso no poco influyó en los nuevos sentimientos vitales de Sokol, así que desde los comienzos de los años cuarenta predomina en él el aislamiento acusador, a lo cual contribuyó también la guerra en Europa.

El año cuarenta cierra el conocimiento intenso de México por parte de Sokol, aunque la vida de este país no deja de ser atrayente para él, surge ante él una nueva realidad, el mundo amenazador de la guerra. A partir de este año, los motivos mexicanos disminuyen, pero de tiempo en tiempo vuelven a aparecer y significan para él una vuelta a los destinos humanos (a las hieles de la vida) en el tiempo de inhumanas catástofes militares.

102 Revista Política, Globalidad y Ciudadanía | Vol. 8, Núm. 15, enero - junio 2022 | ISSN 2395-8448 | http://revpoliticas.uanl.mx/ 


\section{Su Obra Mexicana}

La mayor parte de la obra conocida de Sokol de los años 1940-1941, la forman imágenes de multitudes silenciosas o de marchas fúnebres trágicas como son Monumento (Sobre el compañero muerto, 1940) o el Entierro (1940, título original en español). En ambos casos se trata de dibujos combinados de carboncillo y tizas de color, realizados sobre un fondo de acuarela cubiertos por una capa de goma-laca amarillenta, que da impresión de veladura. Este método de trabajo, que casi no se utilizaba en Checoslovaquia, facilitaba al autor reaccionar rápidamente y sin grandes preparativos a los estímulos de la realidad, y eso con obras acabadas, artísticamente cerradas, es decir no sólo bocetos, le facilitaba también el máximo de posibilidades expresivas, desde un estudio más frágil lírico, hasta la expresión violenta, tormentosa, de una acusación social y personal.

A Sokol le horroriza la sombra de la muerte, o mejor dicho, su culto siempre vivo, una de las características etnográficas mexicanas, no sólo el europeísmo real inaccesible a la fe en el bien y en la salvación que trae la muerte, sino también su propia vida y ligazón con la vida en Eslovaquia, marcan la Cabeza de un desconocido (barniz de goma laca, 1940), el Indio muerto (barniz de goma laca, 1940), y sobre todo - a diferencia de los trabajos anteriores- la viva cara de la india vieja en goma-laca titulada Llanto, con una tristeza sin resignación y sumisión.

Aún porque en cada una de estas obras queda una huella del escepticismo poco advertido del autor, de dudas sobre todo y burlas de sí mismo, la muerte es, en la imaginación de Sokol, un violador, la amistad llena de confianza, con la cual la ven los mexicanos corrientes, le sigue siendo ajena. The golden Lady (La señora de oro, barniz de goma laca, 1940) o Mujer sentada (barniz de goma laca, 1940), - desnudos femeninos modelados con pasta dorada, que salen de un fondo de color verde oliva marrón con un misterio y al mismo tiempo una materialidad terrestre excitante, tal como la sabían hechizar los maestros del barroco-, son un irónico consentimiento de Sokol con la vida. Es interesante comparar este análisis con otro, Radoslav Matušík advierte que "la propia creación gráfica está acompañada, en los años de su estancia en México, y más tarde en los Estados Unidos, de la intensa actividad de dibujante. Sokol trabajaba con carboncillo y con gredas de colores, combina las técnicas. Y así surge The golden Lady (carboncillo, 1940), Un indio muerto (carboncillo, 1940). La concepción de estas obras está relacionada con la opinión gráfica del periodo, pero es más espontánea, más temperamental y expresiva. Principalmente después del estallido de la guerra, a los horrores de la cual Sokol, pese a la distancia de 
Štěpánek., P.

su patria, reacciona inmediatamente con mucha sensibilidad (Una escena del campo de concentración, 1940, etc.)” (Matušík, 1963).

Lo es asimismo el tierno y melancólico dibujo La madre con el niño (1940), cuya línea es dibujada de nuevo con vibraciones y complementada tan sólo con una modelación sobria hecha con la sanguina marrón, la nueva ola de liberación que suena en este dibujo -que se suma a las mejores obras de Sokol es sintomática para el segundo periodo de su estancia mexicana, que se distingue principalmente por su naturaleza psíquica.

En este breve periodo de dos años (desde los finales de 1940 hasta 1942), en la creación de Sokol predomina el dibujo de gran tamaño al carbón libremente trazado, pocas veces terminado con goma laca, y que casi no tiene colorido ablandador. El artista regresa entonces al máximo contraste del negro y blanco para volver a demostrar que el aprovechamiento y el dominio de esta clásica premisa del grabado es una probidad de su creación. En los dibujos de Sokol en este periodo de fuerte expresión, encontramos la capacidad de expresar sentimientos humanos (por ejemplo, Una mujer sentada llorando, 1940, o En el país debe reinar calma y orden, 1941), para lo drástico de estos trabajos no es casual que junto a ellos surja una serie de grabados en linóleo que compensan el drama humano en los dibujos con la vuelta hacia el exotismo del campo mexicano.

La mayor parte de estas hojas de Sokol sigue la suerte de la familia mexicana, y ello más bien con una intención más etnográfica que psicológica, es excepcional la hoja de tres figuras, afinada como una balada titulada Los indios sentados (1940). Estilísticamente diferente y probablemente el primero, es el grabado en linóleo Revolucionarios (1940) que ofrece la posibilidad de hallar no pocos puntos de contacto con la creación gráfica mexicana del Taller de Gráfica Popular, principalmente con la opinión ideológica y plástica de Leopoldo Méndez, Sokol no afinó por casualidad su creación al tono común con Méndez y algunos otros miembros del Taller de Gráfica Popular. Después de su salida de la Escuela de las Artes del Libro y durante todo el tiempo restante de su estadía mexicana, actuaba en el Taller como colaborador activo. Los grabados en linóleo Familia india (1941), indio sentado (1941) y, más que todos, Rancheros (1941) vuelven a recordar los trabajos de los primeros meses de estadía del artista en México.

El linóleo utilizado en México corrientemente para fines creadores, era para Sokol un material gráfico blando que convenía excelentemente al aprovechamiento decorativo, Sokol jamás dejó de ser hechizado por el arte popular mexicano, con su variedad que se desprendía de la unión admirable de la 
vieja cultura india con la tradición artística agresiva y temperamental traída a México por los colonizadores españoles. Vuelve a esforzarse por abarcar plásticamente toda la riqueza de colores y la contradictoriedad interna de la vida en este país lleno de contrastes. El ornamento geométrico, a simple vista sencillo y sin pretensiones, pero infinitamente rico en variantes, utilizado en la fabricación de telas, felpudos, sombreros y objetos de cuero, es para Sokol uno de los estímulos para una visión decorativoexpresiva de los motivos mexicanos. También por primera vez utiliza el elemento geométrico ornamental al tratar el trasfondo neutro en la hoja Rancheros (1941), pero la principal valoración plástica de estos conocimientos la hallamos también más adelante (Šefč́áková, 1964).

\section{Sus Exposiciones Mexicanas}

Se recuerda todavía sus éxitos públicos: en 1938 tuvo una exposición de grabado en el Palacio de Bellas Artes, de México. Y naturalmente, la reproducción de la portada contenía un tema social. Tres años después de su primera exposición en México, Borja (1941) logra exponer en otro sitio, en la Galería de Arte Decoración, que mereció una reseña que vale la pena recordar entera (en el suplemento a este artículo) (Borja, 2019). La exposición fue incluida entre las más importantes del año, aunque las exposiciones con obras de un solo artista fueron numerosas. Según Fernández (2012), se destacaron "las de Juan Soriano, joven pintor que mostró adelanto; la de Raúl Anguiano, otro joven pintor de mérito; la del conocido pintor Carlos Orozco Romero, que presentó una serie de cuadros llenos de encanto y elegancia y la del expresivo artista Koloman Sokol que con sus litografías, aguafuertes y grabados expresa su dramático temperamento” (p.67). Según Benito Rivas, la exposición tuvo un amplio eco en la crítica y en un artículo suyo surgido más tarde (Rivas , 1940), da la palabra al crítico de la revista Romance, posiblemente el pintor y crítico español Ramón Gaya, exiliado en México, en un texto más largo que el suyo propio. Según él:

... "Sokol pertenece a la zona artística contemporánea centroeuropea. El carácter artístico de esta zona está mejor definido por la fuerza que por la gracia. Inquiriendo duramente el carácter de las formas y manifestándolo con vigor seco y preciso, y con entonaciones fuertemente contrastadas. Koloman Sokol es excelente grabador, y o sólo por su visión artística. Busca con frecuencia la expresiónde lo patético; el drama de las formas, de las luces, y de los contrastes de claroscuro, y el drama de la expresión, suelen ser lo que principalmente le atraen. Procedente de un lugar de Europa, en el que la tragedia se abate desde hace un cuarto de siglo largo, su arte está penetrado 
Štěpánek., P.

hasta la intimidad de su ser precisamente en este pathos, de ese drama político y racial y social que agita sin descanso el centro y el oriente de Europa”.

Y continúa explicando que el vivir moderno de las grandes ciudades que según San Agustín son Ciudades del Diablo, tiene para este artista no escaso encanto.

Las fermentaciones de la vida de las grandes ciudades, transpotadas a términos estéticos, se ven en ocasiones en los grabados de K. Sokol". Concluye: "El arte o manera de arte que trae Sokol, no es tan distante del arte o manera de arte mexicano. También el arte mexicano pudiera caracterizarse por su rudeza, por su energía, por el dramatismo y la supremacía de la fuerza sobre la gracia. El arte mexicano hierve, como la ciudad de México, recogiendo en su seno elementos múltiples y heterogéneos, y unificándolos a la postre en un molde complejo, que no pertenece a ninguno de ellos. Así se explica, a nuestro entender, esa asimilación por parte de México de un grabador como Koloman Sokol, y al mismo tiempo la impronta que México va poniendo en sus obras".

Pero con el tiempo Sokol iba cayendo en el olvido: el que mostró la importancia de Sokol para el grabado mexicano del lado mexicano fue el incansable crítico Antonio Rodríguez. En una visión retrospectiva, Barbosa (s.f.) dice sin vacilación que "el grabado mexicano está en deuda, desde hace mucho tiempo, con el extraordinario grabador, Koloman Sokol” (p. 52). Y, da razones contundentes:

El museo de Arte Moderno, en la sala consagrada a la estampo, lo olvida, y en la exposición de grabado que hace poco celebró la UNAM ni siquiera se menona su nombre. Se trata de una injusticia e ingratitud ya que Sokol se integró en forma plena a nuestra vida artística hasta el punto de realizar, entre nosotros, una obra de rasgos netamente mexicanos.

\section{Sokol fuera de México, aún mexicano.}

Sokol participó activamente en la vida artística de México y ocupó en ella una importante posición. Ya en marzo de 1938 tuvo una exposición individual bajo los auspicios del gobierno mexicano en el Palacio de Bellas Artes, en su mayoría de grabados traídos de Checoslovaquia. Todos los años enviaba sus obras a las exposiciones que se celebraban en diferentes ciudades americanas y al Salón mexicano oficial y en 1941 envió, como ya se mencionó, una colección suya para una exposición independiente en Estados 
Unidos (San Francisco). En tanto que hombre y artista cobró afición sincera a México, y si no fuera por los lazos familiares no lo hubiera abandonado en los años de guerra.

Con la salida de México, es como si todas las viviencias se reflejaran en la consciencia del grabador, purificadas de detalles poco importantes y cristalizadas en una imagen plástica, condensada como símbolo. Y ello porque le instruyó el simbolismo de las artes plásticas populares mexicanas. La serie de los grabados en linóleo, relacionados entre sí, que surgieron en los Estados Unidos (1943-1945) y luego también en Checoslovaquia en los años 1945-1946, representa el eterno regreso a los motivos mexicanos (Šefčáková, 1964).

Temáticamente Sokol permanece fiel a las protestas contra el furor humano, contra la guerra. Mientras que en sus cuadros y dibujos más viejos deja la fuente del mal y del peligro fuera de la masa humana y muchas veces fuera del cuadro, después del año 1942 aparece en su obra el motivo de una concreta batalla humana: de los desnudos furiosos, empobrecidos y huesudos que se agitan (La batalla de las mujeres, 1946) o de los cuerpos humanos entremezclados que yacen muertos e inertes, símbolo amenazador de la barbarie fascista (Una escena del campo de concentración, Víctimas, 1945). Tiene como antecedentes el grabado Las mujeres, 1942.

El ciclo de grabados en linóleo que comienza con Picador y La melodía tropical (1943), continúa en 1944 con hojas tituladas Las lavanderas, Baño, Vendedora del sarape y finaliza con Profeta (1946). El autor evoca las escenas de género, así como el carácter del ambiente, uniendo decorativa y simbólicamente detalles concretos y sencillos; su rica asociabilidad aprendió a utilizarla al estudiar el arte indígena mexicano y los tesoros de la escultura negra en los museos. Para mantener en integridad la línea narrativa que determinó con su grabado en linóleo, utiliza un sistema de composición próximo a la perspectiva hierática de las iluminaciones medievales, colocando diferentes personas junto a los indicios del ambiente en el cuadro, de tal manera que su grandeza está en relación directa con su importancia.

En lo que atañe a la técnica, las hojas surgidas en los Estados Unidos están menos relacionadas con el acceso tradicional al material gráfico. El ejemplo de los grabadores mexicanos que trabajaban muchas veces con el buril y combinaban diferentes maneras de procedimiento, incluyendo el aprovechamiento de las estructuras decorativas, no quedó allí sin eco. Sokol, en cada una de sus hojas señala poéticamente menudos episodios de la vida diaria de sus mexicanos, de los cuales no puede olvidarse. En el cuadro Picador vemos una lidia con el toro; el movimiento de los combatientes y el grito del público son, en este caso, problemas principales para el autor, aunque fuera de lo gráfico. 
En la hoja Mercado o Vendedora del sarape, Sokol aprovecha la ocasión de valorar plásticamente el detalle geométrico de las cobijas de lana de manera análoga en La melodía tropical. El sentido por la curiosidad folklórica se une aquí con la fantasía del autor y surge una narración caleidoscópica, dramática, decorativamente desarrollada.

Menos estilizadas son Las Lavanderas y la hoja final del ciclo Profeta que reflejan de manera más evidente, principalmente en el último linóleo, la reminiscencia autobiográfica, concebida baládicamente, de un país de muchas caras y la actuación de Sokol en él.

En 1945, surgen las dos variantes gráficas de la leyenda sobre el héroe nacional eslovaco Jánošík. En los dos casos, Sokol observa concientemente el proyecto habitual en la composición de los temas de Jánošík en la pintura popular eslovaca sobre vidrio. Las hojas siguen una continuidad de estilo con los grabados en linóleo mexicanos. Est8a estrechamente ligadas con dibujos del mismo tema y con el ciclo El Trópico (Šefčáková, 1964, p.26). Su próxima obra se desarrollará de manera diferente, según indica La familia, del año 1945.

Sokol y TGP

Sokol llega a México en 1937, poco antes de que se estableciera el Taller de Gráfica Popular (1938) bajo la dirección de Leopoldo Méndez, por eso no podemos pasar por alto, aunque fuera solo con una mención, la relación de Sokol con este Taller, existen escasas informaciones acerca de su colaboración en él.

Norbert Frýd se limita a señalar que “...de entre unos veinticinco huéspedes (incluyendo mexicanos) es necesario mencionar al grabador eslovaco Koloman Sokol, quien durante la guerra colaboraba estrechamente con el TGP” (Frýd, 1955). Esto se debe sin duda a que en los años cincuenta se veía con mala cara a todo checoslovaco emigrado. Más tarde, Ladislav Saučin dirá:

“...A finales de su estancia mexicana trabajó asimismo en el mundialmente conocido Taller del grabado popular, que hasta hoy es el semillero del grabado revolucionario mexicano." (Saučin, 1962).

Es precisamente aquí donde hay lagunas para investigar: hasta qué punto se mostró la influencia de Sokol y, al revés, como influyó la colaboración con el Taller en él, aunque la línea de su influjo está dada sobre todo por los nombres de sus alumnos: Abelardo Ávila, Pedro Castelar, Mariano Paredes, José 
Julio Rodríguez y Francisco Vázquez, por orden alfabético, quienes asimilaron su eneseñaza. Antonio Rodríguez lo explica de tal forma que Sokol "fusionó la técnica de la enseñanza... con la incitación al conocimiento de la vida en México”; da a continuación un ejemplo: Abelardo Ávila, según su opinión, refleja "una influencia positiva, sanamente asimilada, del excelente grabador eslovaco" (Barbosa, s.f.).

Pero por suerte tenemos un testimonio claro de que hubo contacto directo de Sokol y sus alumnos con el Taller de Gráfica Popular, el mismo año 1941 en que Sokol se presenta con su exposición individual en la Galería de Arte Decoración, un poco más tarde, en junio del mismo año, participa en una exposición colectiva junto con su esposa Lydia (de apellido Kratina) y de otro checoslovaco José Otáhal, de quien sabemos poca cosa, en la misma galería. Aparte de sus alumnos y colaboradores, Abelardo Ávila, Pedro Castelar, Francisco Díaz de León, Mariano Paredes y Francisco Vázquez, estuvieron los siguientes miembros del TGP: Carlos Alvarado Lang, Raúl Anguiano, Angel Bracho, Leopoldo Méndez, y Alfredo Zalce (Fernández, 2012).

\section{Sokol en Eslovaquia}

Como ya dijimos, el cambio de la situación política interna en México tuvo por consecuencia que el matrimonio Sokol decidiese partir de México para los Estados Unidos, donde se queda hasta 1946. Es que, en el I Congreso de intelectuales y científicos eslovacos celebrado en 1945, apenas terminada la II Guerra Mundial, en la ciudad de Banská Bystrica, los presentes decidieron invitar a todos los intelectuales activos que habían emigrado al extranjero para que pudiesen contribuir con su trabajo a la formación de la cultura eslovaca después de la guerra. Entre los primeros estuvo Sokol, que retornó a Eslovaquia en octubre de 1946. Sin embargo, los cambios ocurridos en su tierra natal durante su ausencia fueron tan importantes que tuvo que conocerlos paso a paso. Los problemas de familia, las tareas organizativas y pedagógicas, no le permitieron dedicarse ese año a la creación artística como en los años pasados.

En una entrevista publicada a su llegada a Eslovaquia, Smrek (1946) citando a Sokol quien dice: “desde el comienzo he pensado en regresar, pero no era fácil pensar en la partida, ya que, en México, como profesor de la Escuela Superior de las Artes Plásticas, encontré un vasto campo de actividad y también preparé un considerable número de grabadores modernos -calculo el número de mis estudiantes en más de 100 - fue toda una generación. A mí me consideraban como el renacimiento del grabado mexicano o de América en general, tanto la del Norte como la del Sur, latina o anglosajona. En México me esperan, por lo menos de visita, la que tuve que prometer... La verdad es que esta visita a México no puede efectuarse tan pronto, la prometí para dentro de cinco años... Creo que desde mi 
Štěpánek., P.

punto de vista - y no solamente desde el mío-, los países más interesantes del mundo son justamente México y China, principalmente por su composición social: en uno los mestizos y los indios, en la otra los “culi” chinos. Después por el rasgo especial de uno y otro país, y además la antigüedad de la cultura o de varias culturas antiguas: en México las naciones de los Incas, los Mayas, los Aztecas, en China las naciones antiguas desde los tiempos de Confucio..." Y Sokol agrega: "Me he traído asimismo unos 150 cuadros (subrayado de PŠ, en realidad grabados) procedentes de mis alumnos de México."

En mi búsqueda de obras mexicanas no he encontrado ninguno; es probable que Sokol se llevase esta colección de dibujos a Estados Unidos a su archivo (en Tucson). - A su vez, sus alumnos, cuando se organizaron en la Sociedad de Grabadores de México, le nombraron a Sokol Socio Honorario en una carta fechada el día 23 de febrero de 1948, es decir, dos días antes del golpe de estado comunista en Checoslovaquia.

Ahora bien: antes de finalizar me permito no solamente sugerir sino concretamente proponer que se estudie el papel de Koloman Sokol desde el punto de vista mexicano, a través de los testimonios conservados que, supongo, no serán pocos. Quizás sea un poco exagerado afirmar que Sokol es "la personalidad fundadora no solamente de las artes gráficas eslovacas modernas, sino también de las mexicanas.” (Práce, 1978). Pero en algún aspecto esta afirmación no está muy lejos de la veradad. Que se estudie, entonces, su influencia en los alumnos (que yo desconozco y que podrían apartar testimonios directos) y por los reflejos de su obra. Esta será probablemente la mejor manera de contribuir a conocer la verdadera dimensión de los destinos comunes del arte checoslovaco y mexicano.

No podemos pasar por alto lo que consideró Antonio Rodríguez como fundamental pero lo que no se había llevado a cabo todavía: “(...) será, de justicia realizar en México una exposición homenaje a su obra y a su labor pedagógica, a fin de situarlo entre los maestros provenientes de otros países Jean Charlot, Silvia Santa María, que han ejercido una influencia positiva en nuestro grabado”. En el archivo Sokol se guarda una carta firmada el día 6 de diciembre de 1948 por Carlos Chávez, recomendándole a Sokol que se comunique con Fernando Gamboa, a la sazón director del Museo de Bellas Artes, “para ultimar los detalles”. El último libro eslovaco es de Jančár, I. 2007. (Barbosa, s.f.).

\section{Suplemento Documental}

Francisco Borja Bolado, “La exposición de Sokol”. Social, marzo 1941: 
En la Galería de arte Decoración que fundó y dirige con progresivo éxito Don Eduardo $R$. Méndez, acaba de ser inaugurada la exposición de Koloman Sokol, destacadísmo artista checo (en realidad debiera figurar checoslovaco, nota PŠ), cuyos trabajos al aguafuerte, grabado en madera, acuatinta, etc., son mundialmente famosos.

Sokol ha expuesto ya en nuestro país, pero creemos que la obra que presenta en esta vez supera a la exhibida en años pasados. No se trata, por supuesto, de nuevos rumbos, ni de otra técnica, ni del mejor dibujo, el que ha dado ya categoría de primer plano a sus obras en las principales diudades de Europa y Estados Unidos. Supera porque ha seleccionado ahora lo trascendental de su labor de los últimos tiempos y ésto, se comprenda, hace que el conjunto tenga una calidad y unidad extraordinarias.

La obra de Sokol - "no apta para menores... de espíritu", - es una de las realizaciones dramáticas más impresionantes. Fuerte, honda, dolorosa, es interpretación y síntesis de todo lo amargo. En las plumas y en los buriles de Sokol, andan las voces de Baudelaire y de Verlaine, y, a veces, al espíritu atormentado de Goya. Estamos, pues, frente a obra de realidades angustiosas, que oprime y desanima, pero que todos deben de ver, en espacial aquellos para quienes parece haberse hecho famosa la frase del ministro de Luis XIV: "Sire, la miseria existe".

En la exposición de Sokol que será clausurada el día 31, figuran, entre otras obras, las que aquí reproducimos (nota de PŠ: ninguna reproducción ha sido adjunta), y que son, en su orden: "Sentados" tema de la dolorosa resignación; "Paralítico" - una aguatinata que tortura y enferma; "Campesinos" fraternidad sin tránsito de esperanza; "Moribunda" - casi una estampa bíblica, tema para la pesadilla de los felices; y finalmente, El último goce - sueño, anticipio de muerte redentora, breve escapada de la realidad, don que todavía no han podido quitar a los que sufren.

\section{3.- MÉTODO}

Con relación a la metodología utilizada, este trabajo tiene su origen en una investigación cualitativa con análisis de documentación primaria. En una primera etapa el trabajo cualitativo desarrollo exclusivamente la búsqueda documental de obras originales del grabador checoeslovaco Koloman Sokol, basada en sus obras de colecciones mexicanas, exposiciones y su influencia en el grabado mexicano. Posteriormente para el análisis de la información se utilizó la técnica de revisión documental mediante el estudio de la prensa diaria, revistas especializada y monografías. Finalmente se describe de forma detallada los elementos principales de la obra del autor y el impacto en legado mexicano. 
Štěpánek., P.

\section{4.- CONCLUSIONES}

En 1931 terminó sus estudios en arte, exponiendo ese mismo año con el grupo Hollar, en Praga, donde estudió con los mejores grabadores especilizados; estuvo ligado sobre todo con Jan Rambousek, el principal artista de la escuela social checa de grabado. Sokol llegó a México el 20 de junio de 1937, en virtud de un programa de intercambio cultural-pedagógico entre México y Checoslovaquia, como resultado de una exposición en México del grupo de grabadores checos Hollar, de mucho éxito.

La petición había sido hecha por Francisco Díaz de León, director de la Escuela de Artes del Libro en la Ciudad de México. Una vez instalado en la capital de México, Sokol fue encargado de la dirección de la cátedra de grabado del libro. Su actividad pedagógica en México duró hasta 1941, tres años más del compromiso inicial, puesto que la estancia era por un año. Sokol era uno de los pocos artistas de Checoslovaquia que trataba en sus obras los temas sociales y mexicanos. Los tipos populares fueron continua fuente de inspiración para Sokol.

Tras su salida de la Escuela del Libro y durante el tiempo restante de su estadía en el país, fue colaborador del Taller de Gráfica Popular. Trabajó el linóleo y la madera en especial, materiales que consideraba excelentes para el desarrollo de una obra inmediata. Los temas sociales le unieron a la ideología de los artistas del TGP, con el cual colaboró en calidad de grabador huésped. Dado que expuso en el Palacio de Bellas Artes, tuvo bastante aceptación en México, aunque con el estallido de la Segunda Guerra mundial prefirió irse a los Estados Unidos, de donde era du mujer, Checa de nacimiento. Al terminar, el matrimonio volvió a Checoslovaquia, pero como no ha sido nombrado profesor de la Academia de Bratislava, emigró, esta vez noc con definitiva, a Estados Unidos. Pero toda la vida, Sokol recuerda en su obra su estancia en México. Murió a sus 101 aňos en Tucson, Arizona, el día 12 de enero de 2003. Este estudio aporta algunos datos nuevos sacados a la luz por el autor durante su estancia en México, en 2015, invitado por la Universidad Iberoamericana de México.

En diciembre de 2002, la contribución de Sokol a las artes y la cultura fue honrada con la designación de la Galería de la Cancillería en la Embajada de Eslovaquia en Washington, D.C. como la Galería Koloman Sokol. En 2002, la televisión eslovaca produjo un documental titulado "Koloman Sokol: Z labyrintu sveta do raja duse" (Del laberinto del mundo al paraíso del alma). El legado artístico y humanístico de Sokol sigue influyendo profundamente en las generaciones venideras. 


\section{REFERENCIAS}

Barbosa, A. (s.f.). La estampa y el grabado mexicanos. tradición e identidad cultural. http://csh.izt.uam.mx/sistemadivisional/SDIP/proyectos/archivos_rpi/dea_35147_773_511_11_ 1_LIBRO\%20LA\%20ESTAMPA.pdf

Beňovský, J. (2009). Koloman Sokol - umelec svetového významu. https://www.picpiestany.sk/fileadmin/pic/akcie/msks/msks_2013/koloman_sokol_2013.pdf

Blaisten, R. (2011). Francisco Díaz de León, 1897-1975 (Colección Blaisten). https://museoblaisten.com/Artista/144/Francisco-Diaz-de-Leon

Borja Bolado, F. (2019). La Exposición de Sokol. Social.

Díaz de León, F. (2021). Demasiado Lineal. www.elem.mx/autor/datos/294

Diario Práce (1978). La sigla AB, 29. 12.

Fernández, J. (2012). Catálogo de Exposiciones de 1941. Anales Del Instituto de Investigaciones Estéticas, 3(9), 67-89. https://doi.org/10.22201/iie.18703062e.1942.9.321

Frýd, N. (1955). Mexická grafika. Státní nakladatelství krásné literatury, hudby a umění. Praha Hložník, V. (s.f.). Introducción al libro de Šefčáková. Bratislava

Jančár, I. (2007) Koloman Sokol. Bratislava, Editorial Slovart.

Macurová, K. (2010). Koloman Sokol vkontexte moderného mexického umenia. https://www.library.sk/arl-vsvu/en/detail-vsvu_un_cat-0033906-Koloman-Sokol-v-kontextemoderneho-mexickeho-umenia-teoreticka-cast-dizertacnej-prace-Viva-Mexico/

Macurová, K. (2011). Koloman Sokol v Mexiku (Koloman Sokol en México). https://www.goodreads.com/book/show/13590069-koloman-sokol-v-mexiku

Matušík, R. (1963). Sokolove póly (Los polos de Sokol). Kultúrny život.

Orlov, A. (1956). Historia secreta de los crímenes de Stalin. Populibros La Prensa.

Rivas, B. (1940). Koloman Sokol, maestro grabador.

Saučin, L. (1962). Nad šestdesiatkou K. Sokola (El sexagenario de K. S.). Pravda.

Šefčáková, E. (1963). Koloman Sokol. Bratislava.

Smrek, J. (1946). Koloman Sokol sa vrátil (K. S. ha vuelto). Elán.

Sokol, K. y Díla, C. (1978). Una selección de un trabajo de toda la vida. Antivariát Valentinská.

Štěpánek, P. (2002). El grabado mexicano y la enseñanza de Koloman Sokol en México. IberoAmericana Pragensia.

Tokárová V. (1962). Jubileum K. Sokola (Aniversario de K. Sokol). Bratislava. 